\title{
DOS OBRAS DEL ARQUITECTO AZPIAZU ESPAÑA
}

\author{
(TWO WORKS OF THE ARCHITECT AZPIAZU. SPAIN)
}

\section{RESUMEN}

Se presentan en este trabajo dos obras recientes del Arquitecto José Ramón Azpiazu. El interés de cada una de ellas radica en aspectos puntuales, con soluciones constructivas de cierta originalidad:

- En la primera, EDIFICIO DE OFICINAS EN SANTANDER, interesa de modo especial el planteamiento adoptado para el refuerzo de la estructura de madera existente realizado a base de elementos de acero laminado.

- En la segunda, SUCURSAL DE BANCO EN ORIHUELA, el mayor interés radica en la solución constructiva y formal de la escalera helicoidal de hormigón armado, ejecutada sin vástago central.

\section{SUMMARY}

Two recent works of the Architect J. R. Azpiazu are shown in this issue. The interest of each of them is based in punctual aspects with original constructive solutions:

- At first, BUSINESS BUILDING IN SANTANDER, the project is very interesting mainly by the planning and design of the structure in wood reenforcement with laminated steel elements.

- In the second, BANK OFFICE IN ORIHUELA, the interest of the constructive and formal solution in the helicoidal stair in structural concrete, without central element is the main subject.

\section{EDIFICIO DE OFICINAS EN SANTANDER (CANTABRIA)}

\author{
José Ramón Azpiazu Ordóñez y Javier González de Riancho, Arquitectos \\ Gumersindo Domínguez y Rafael Buzón, Ingenieros
}

El edificio está considerado de interés histórico-artístico, siendo su estructura de madera de roble y la fachada de fábrica de ladrillo enfoscada con mortero de cemento y zócalo de piedra de escobedo.

El local tenia dos plantas y habia que ampliarlo por exigencias de superficie con una entreplanta parcial (cabrete) con el fin de sacarle el máximo rendimiento po. sible.
El principal problema fue estructural, debido a que los pilares son de madera de roble y terminan en un plinto de piedra apoyado sobre muro de mampostería que, se supone, estará cimentado sobre pilotes.

Teniendo esta estructura como base, había que intercalar entre las plantas baja y primera una entreplanta parcial, que no superara el $50 \%$ de la superficie total y cuya altura libre tenía que ser superior a dos metros. 


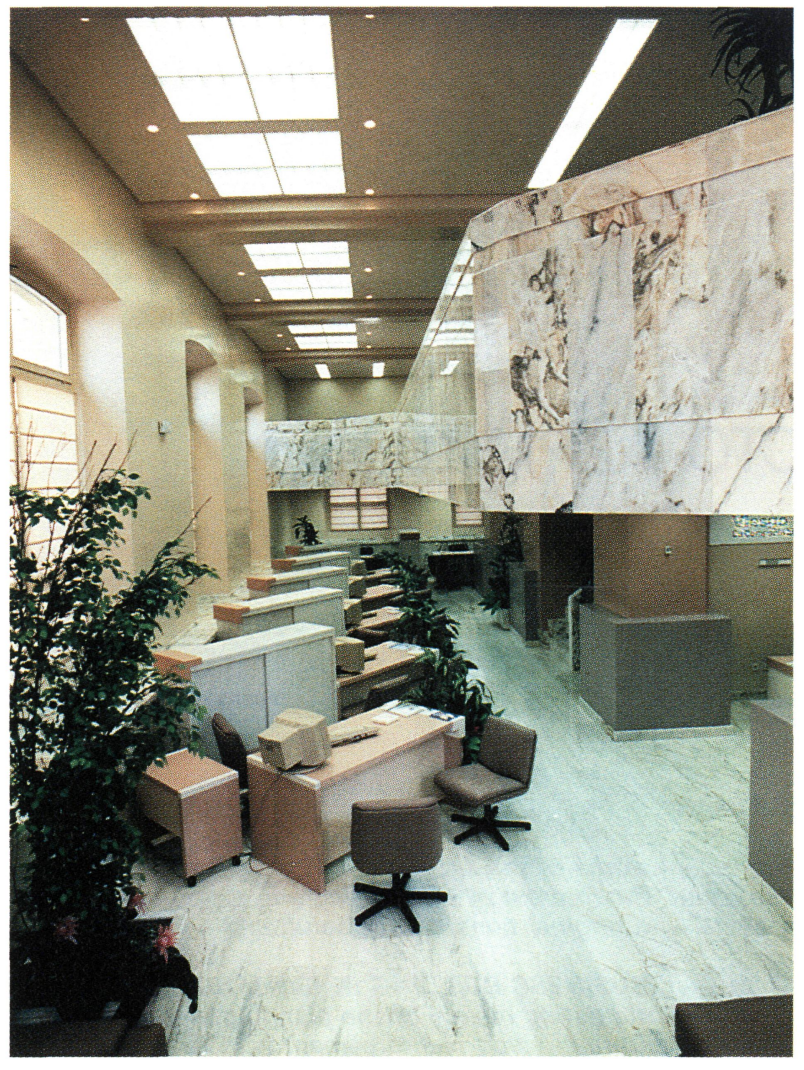

Al no tener altura suficiente la planta baja, hubo que bajar el nivel del suelo $0,90 \mathrm{~m}$, nivel permitido por la cimentación, tanto de los muros de fachada, como de los pilares centrales.

Los plintos de piedra que unen los pilares con la cimentación se han reforzado mediante un zuncho de hormigón armado formando un doble dado: el más fino, situado en la parte superior abarca el plinto de piedra, y el más grueso, situado en la parte inferior corresponde a la parte de cimentación de mampostería de piedra que ha quedado exenta al rebajar el nivel del suelo de la planta baja.

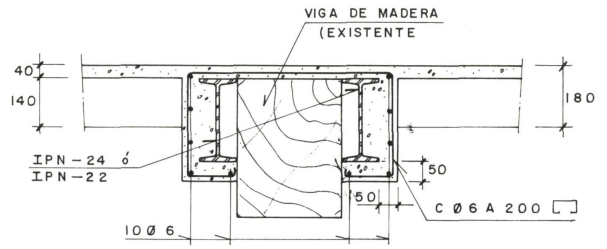

DETALLE RECUBRIMIENTO DE VIGAS

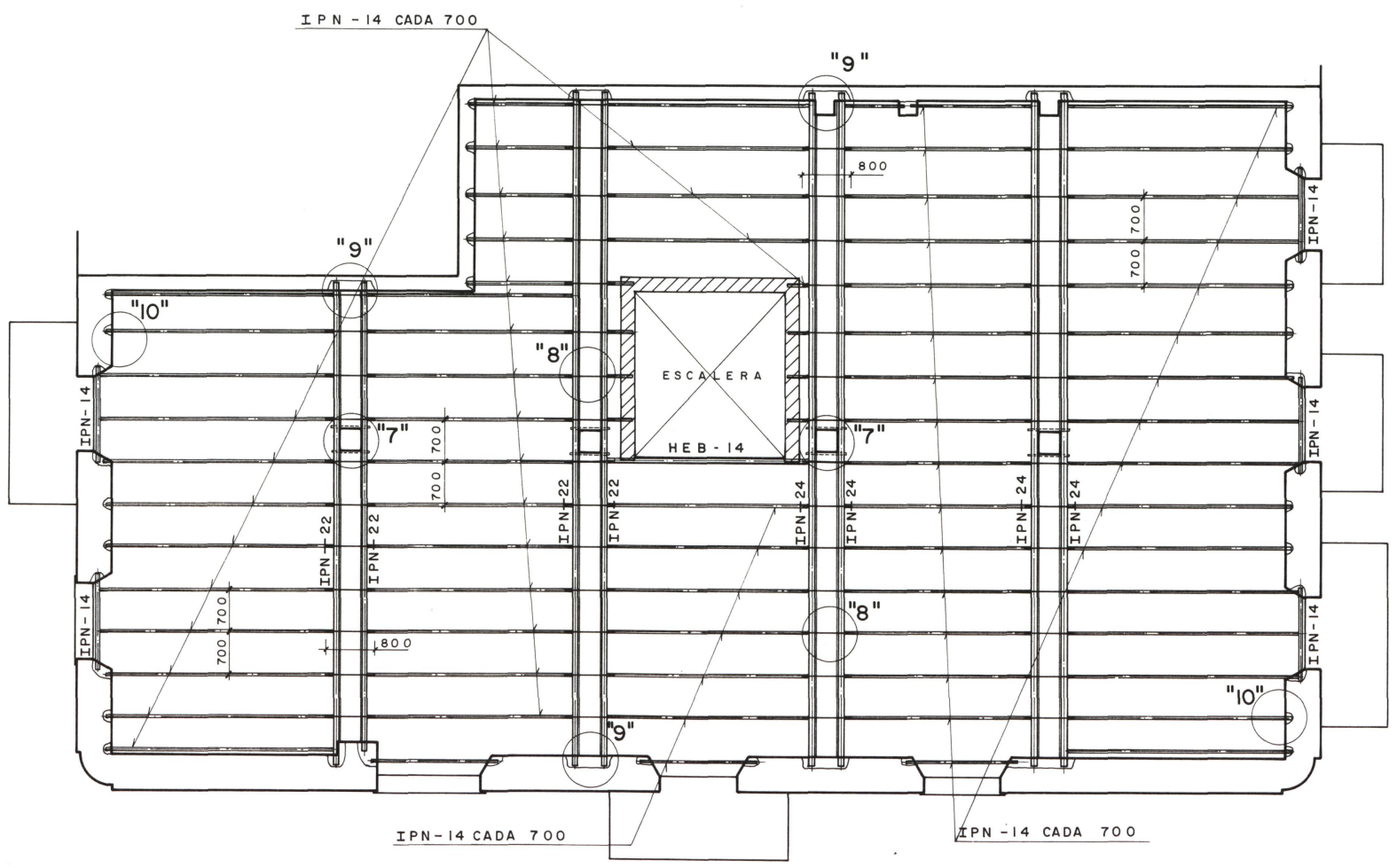

PLANTA PRIMERA 


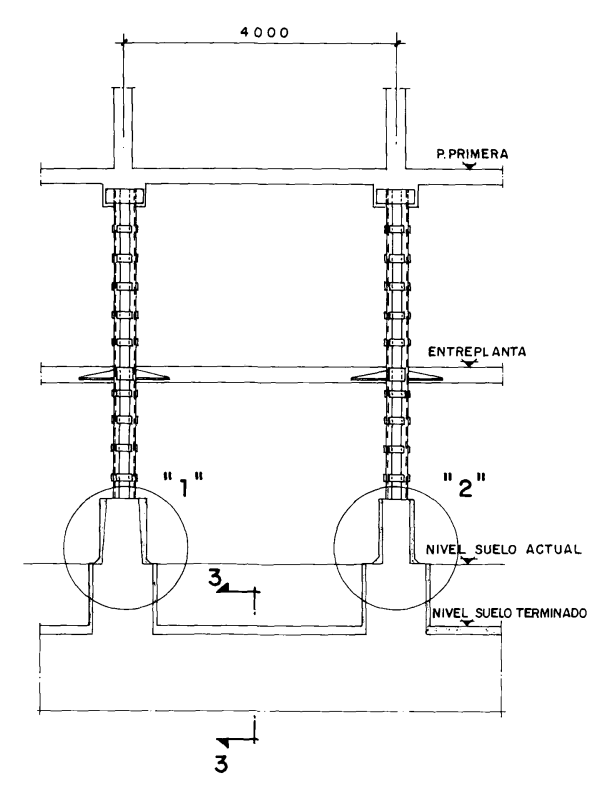

ALZADO PILARES

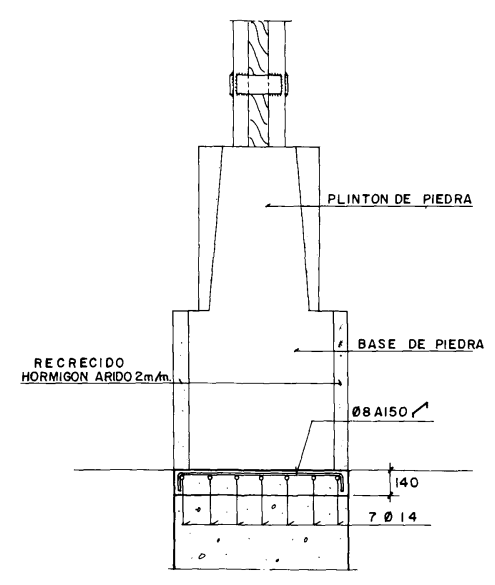

SECCION $3-3$

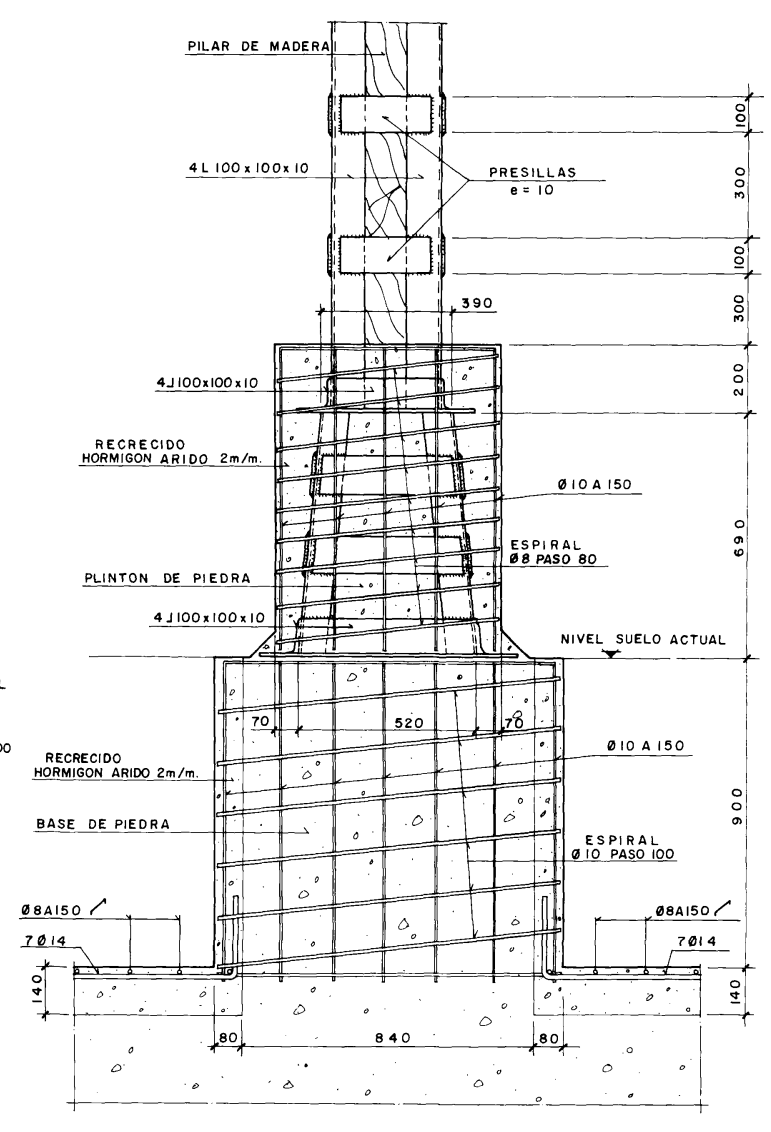

SECCION

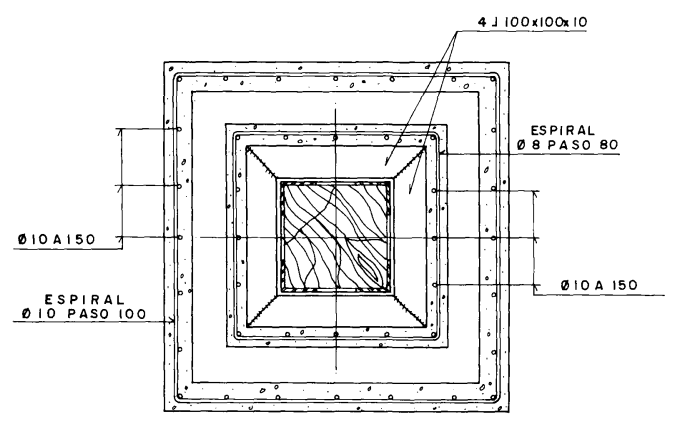

$\underline{P L A N T A}$

DETA LLE-"I" 

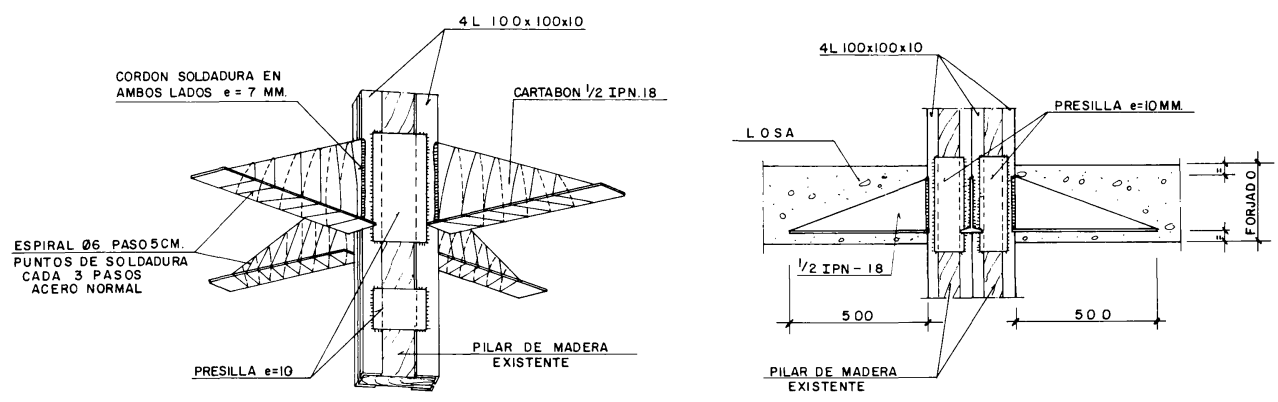

DETALLE DE CAPITELES EN PILARES
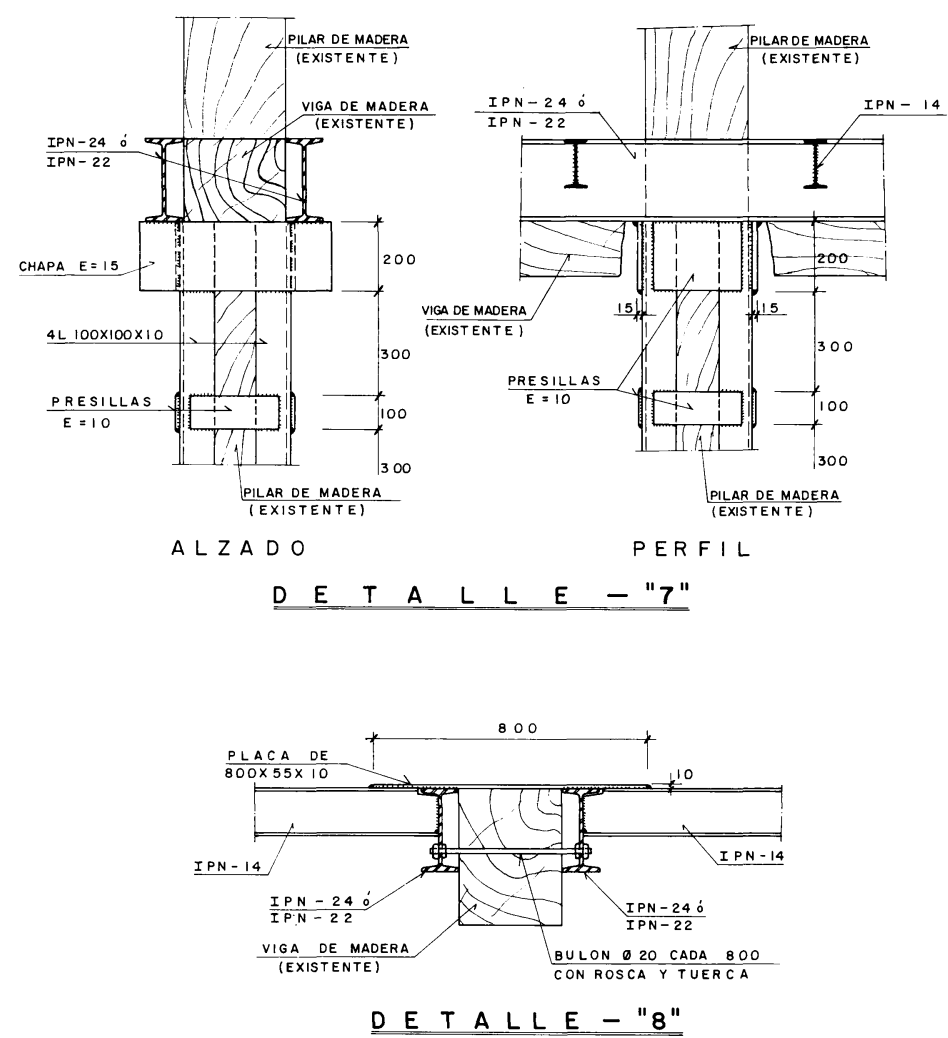

Los pilares se han zunchado con angulares de hierro en las esquinas y presillas de palastro soldadas a estos angulares.

Las vigas de madera del suelo de la primera planta se han reforzado con perfiles metálicos doble $\mathrm{T}$.

El nuevo forjado de la entreplanta está formado por losa de hormigón armado empotrada en los muros existentes y entrelazada con los pilares centrales mediante capiteles, formados por palastros en forma de cuña

(c) Consejo Superior de Investigaciones Científicas Licencia Creative Commons 3.0 España (by-nc) (cuatro en cada pilar, soldados a los angulares de las esquinas de los pilares).

La escalera que une las tres plantas se ha situado al fondo, entre los dos pilares centrales y los servicios de cada planta se han colocado detrás de la escalera.

La fachada se ha respetado conservando el mismo aspecto que tenía, habiendo variado únicamente la am. plitud de los huecos.

La decoración ha corrido a cargo de M. Isabel Rodríguez Gulmain.

http://informesdelaconstruccion.revistas.csic.es 


\title{
SUCURSAL DE BANCO EN ORIHUELA (COMUNIDAD VALENCIANA)
}

\author{
José Ramón Azpiazu, Arquitecto \\ Gumersindo Domínguez y Rafael Buzón, Ingenieros
}

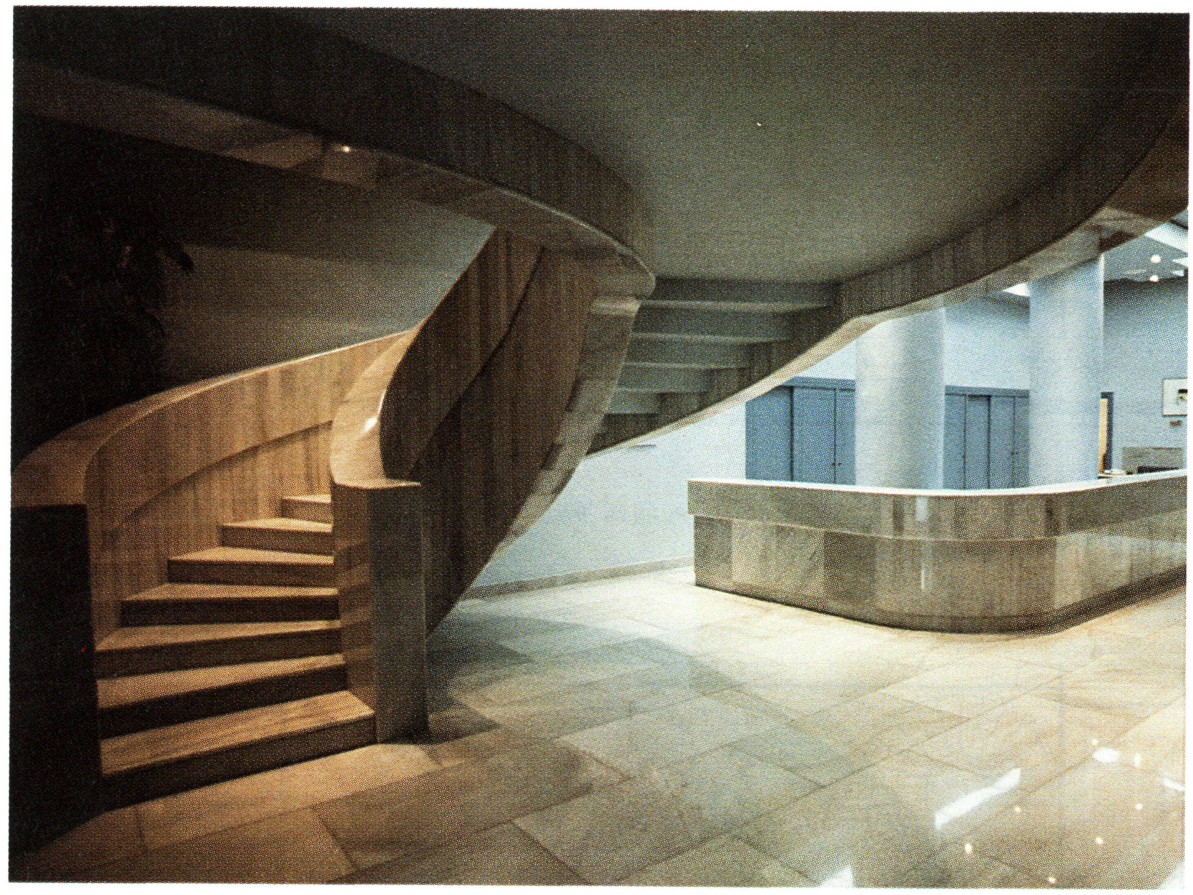

El local donde se ha instalado esta sucursal está situado en un edificio de nueva construcción, de gran calidad, con fachada a la plaza principal de Orihuela, Alicante.

La planta es de forma trapecial con fachada principal de $8,50 \mathrm{~m}$, fachada posterior de $6,40 \mathrm{~m}$, fondo de $31,50 \mathrm{~m}$ y altura libre de 5,09 metros.

El elemento más representativo del local es la escalera principal, de estructura de hormigón armado, revestida de mármol Makael especial. Esta escalera no sólo

(c) Consejo Superior de Investigaciones Científicas Licencia Creative Commons 3.0 España (by-nc) es el foco decorativo y escultórico del proyecto, sino que también presenta la mayor dificultad bajo un punto de vista estructural.

Estructura helicoidal autoportante que apoya en una losa en voladizo de $5 \mathrm{~m}$ de longitud.

El proyecto de esta escalera, por su diseño, geometría y condiciones singulares de sustentación, tiene un cálculo complejo con dificultades en la determinación de los esfuerzos.

http://informesdelaconstruccion.revistas.csic.es 

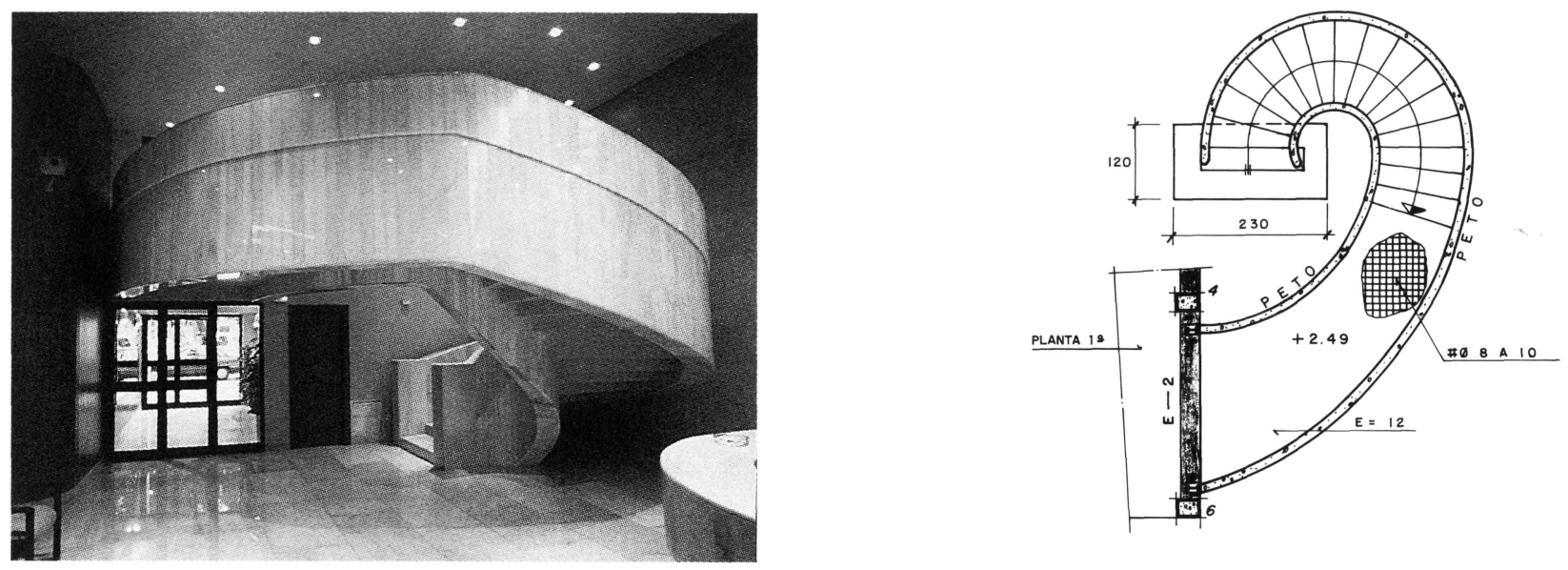

PLA N T A

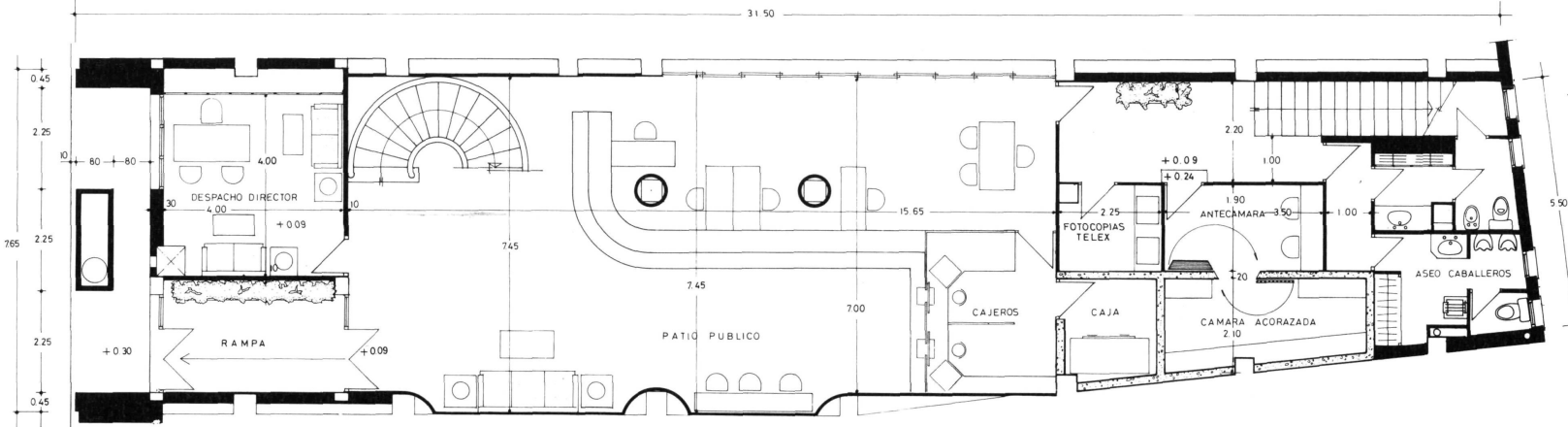

PLANTA BAJA

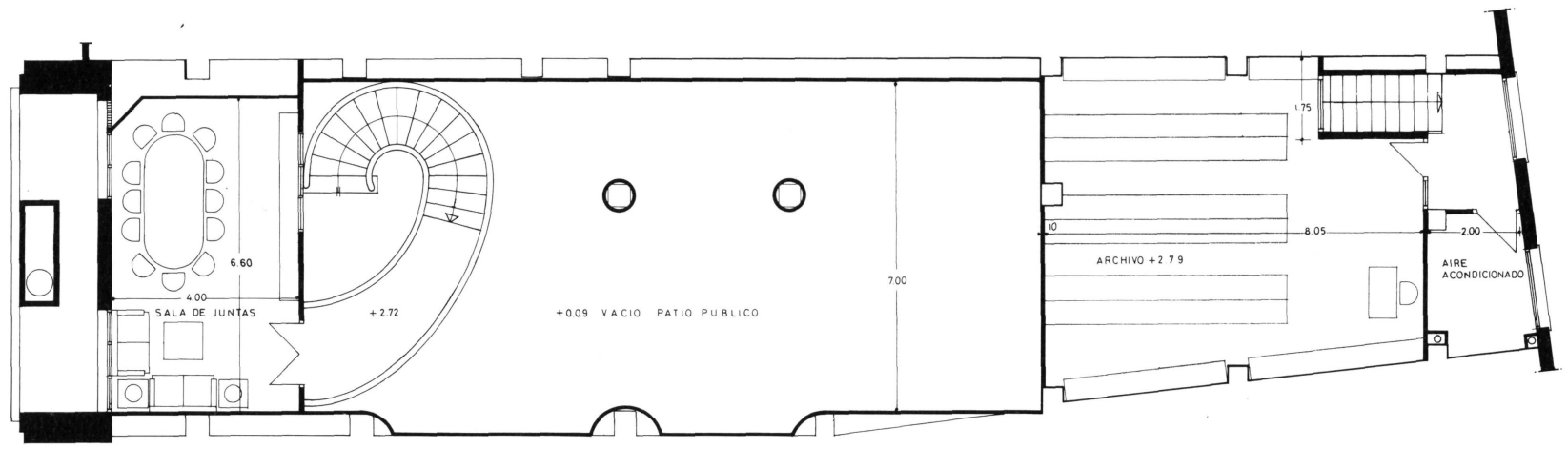

PLANTA PRIMERA

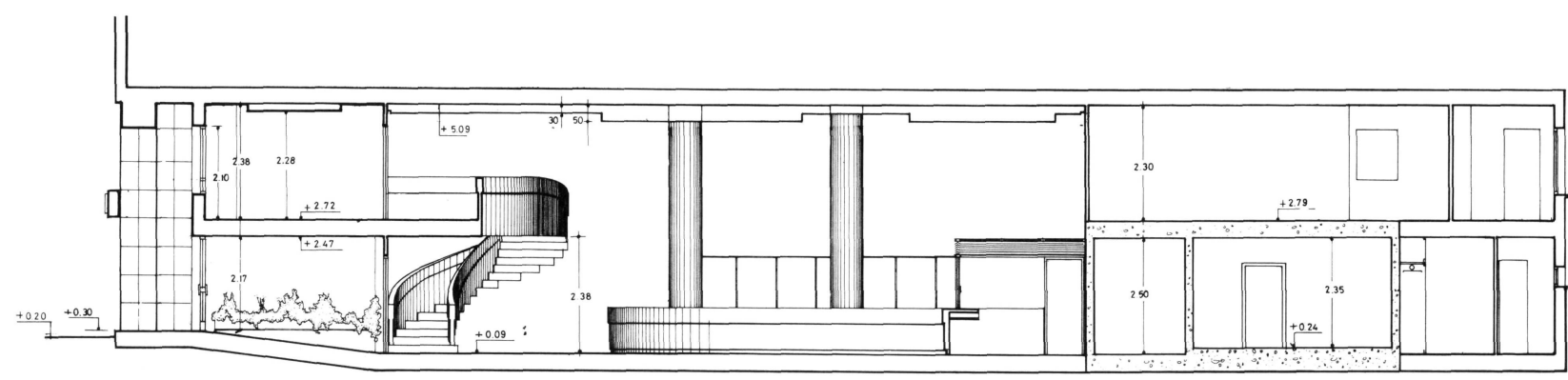

SECCION LONGITUDINAL 

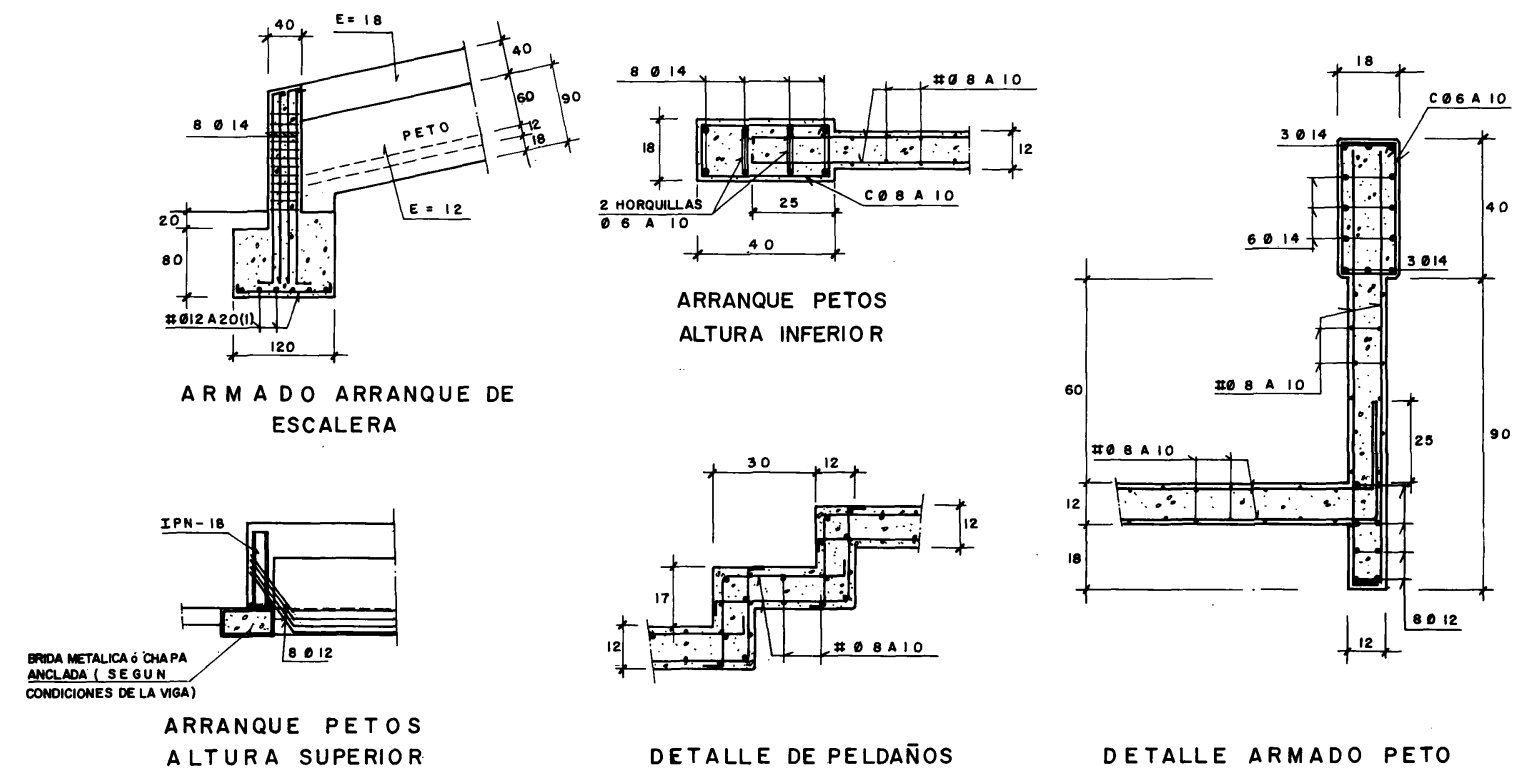

DETALLE DE PELDAÑ̃S

DETALLE ARMADO PETO

A R M A D O

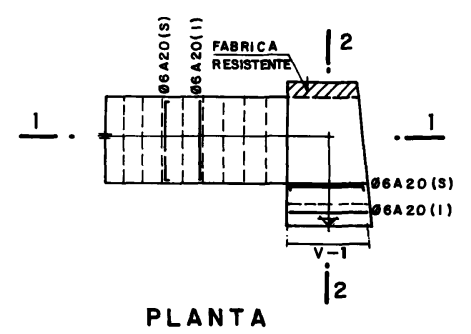

PLANTA

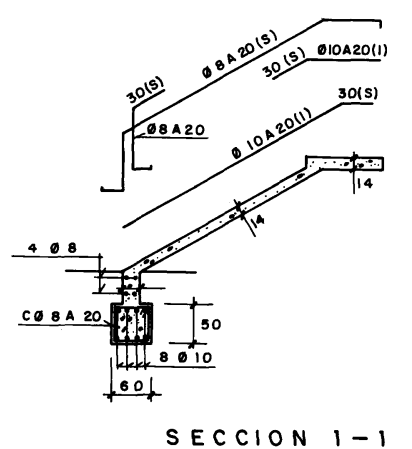

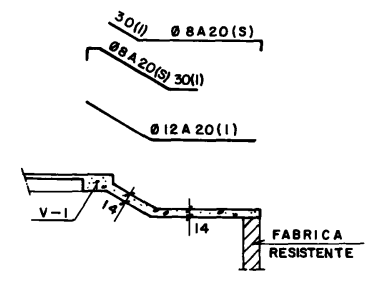

SECCION 2-2

\section{ARMADO ESCALERA-2}

Se ha abordado el cálculo en ordenador, partiendo de elementos lineales triangulares, tanto en planta como en alzado, en reproducción simplificada de su geometría, simulando los pesos en los nudos. En realidad se han considerado como elementos resistentes los antepechos (vigas con formas rectas y curvas sometidas a esfuerzos de flexión y torsión), que soportan el peso de los escalones y mesetas.

Los resultados obtenidos pueden alterarse y ser distintos a la realidad, precisamente por la ficción y sim- plificación que se hace en el cálculo, ya que pueden aparecer esfuerzos secundarios de difícil valoración. Por ser un tipo de estructura tan especial, se abordó su construcción en plan experimental, realizando posteriormente pruebas de carga a su terminación y, al no aparecer ninguna anomalía, se la dio por válida.

Además de los pesos propios, las cargas consideradas han sido $80 \mathrm{~kg} / \mathrm{m}^{2}$ de pavimento, y sobrecarga de 300 $\mathrm{kg} / \mathrm{m}^{2}$. Hormigón y acero $\mathrm{H} 200$ y AEH 5.000 , respectivamente. 